\title{
Macroeconomia do crescimento: reposicionando a estratégia na crise
}

\author{
João Basilio Pereima Neto* \\ Fábio Dória Scatolin ${ }^{* *}$
}

\begin{abstract}
RESUMO - Este artigo trata das opções de estratégias de financiamento sustentado do crescimento econômico adotadas pelos países. As estratégias de financiamento estão articuladas com o regime cambial, com a capacidade de geração de poupança interna e externa e com as condições de equilíbrio da balança de pagamentos. Argumenta-se que os modelos de crescimento com poupança externa, justificáveis no período de substituição de importações, são também responsáveis pela geração de um processo de crescimento cíclico que alterna expansão com estagnação, quando não recessão, por suas contradições internas. Ao fim apresenta argumentos em favor da adoção, pelo Brasil, de um modelo baseado em geração de poupança interna e não externa compatível com a situação da economia mundial vigente no início do século XXI pós-crise financeira.
\end{abstract}

Palavras-chave: Crescimento. Poupança. Câmbio. Balanço de pagamentos.

\section{INTRODUÇÃO}

As diferentes estratégias de crescimento econômico adotadas pelos países em desenvolvimento ao longo dos últimos cinquenta anos conduziram estes países a trajetórias distintas com resultados diferentes em termos de melhoria nas condições de vida da população. Alguns se desenvolveram mais que outros. Os países asiáticos, mais bem sucedidos, adotaram modelos de crescimento liderados pelas exportações de manufaturados e apoiados por financiamentos obtidos por meio de superávits na balança de transações correntes e na geração de poupança interna. Uma política de câmbio competitivo foi o elemento central desta estratégia. O Brasil e outros países da América latina ao contrário, nos momentos em que adotaram explicitamente uma estratégia de crescimento, o fizeram utilizando um modelo de crescimento com ênfase no mercado interno com geração de déficits em transações correntes desde os anos 70, o que exigia obtenção de poupança externa financiada na forma de empréstimos e atração de investimento estrangeiro. A mesma estratégia foi repetida nos anos 90 e mais recentemente no governo Lula. Uma política deliberada de valorização do câmbio foi importante neste processo. Como consequência o

\footnotetext{
* Doutorando do Programa de Pós-Graduação em Desenvolvimento Econômico da UFPR e Professor Assistente do Departamento de Economia da mesma instituição. Endereço eletrônico: joaobasilio@ufpr.br.

** Doutor em Economia pela University of London. Professor do Departamento de Economia da UFPR. Endereço eletrônico: scatolin@ufpr.br.
} 
crescimento médio brasileiro, nos últimos 30 anos e especialmente nos últimos 15 anos, foi menor que o crescimento médio dos países emergentes de forma que em termos relativos o país perdeu posição no ranking mundial. A explicação para os diferentes resultados observados decorre da adoção de diferentes regimes macroeconômicos que deram suporte a um e outro modelo de crescimento.

A escolha entre um e outro modelo de financiamento do crescimento, com recursos internos ou externos, com déficits ou superávits em transações correntes, é um problema de economia política que revela de um lado o entendimento das coalizões de forças e interesses que dão sustentação a cada governo e de outro lado as oportunidades de inserção na economia mundial que as dotações de fatores e a estratégia perseguida possibilitam na história dos países. A opção adotada pelo Brasil desde os anos 1970 e que avançou nos governos FHC e Lula foi a do financiamento do crescimento com poupança externa, o que explica o baixo desempenho do país na grande onda de crescimento observada até 2007, antes da deflagração da crise financeira. Mais recentemente o Brasil cresceu entre 2003 e 2008, não porque houve um esforço estratégico concentrado e orientado ao crescimento. O país cresceu, a despeito de políticas fiscais (superávits primários), monetárias (juros reais altos) e cambiais (valorização) contracionistas, porque foi literalmente abraçado pelo crescimento mundial e empurrado adiante. Fosse outro o contexto mundial esta arquitetura macroeconômica teria produzido uma redução do nível de atividade.

Mas se o modelo de crescimento com poupança externa já não era adequado antes, a mudança do cenário mundial após 2008 torna o modelo mais anacrônico ainda. O Brasil, que não mudou em nada o regime macroeconômico vigente desde a estabilização de FHC, deve repensar e alterar seu modelo de crescimento, pois a crise financeira alterou profundamente as regras do jogo. A alternativa para o Brasil não perder de todo sua capacidade de crescimento é compatibilizar um modelo de crescimento com geração de poupança interna, o que requer políticas macroeconômicas monetárias e cambiais adequadas a este objetivo. No restante deste artigo, apresentamos as justificativas para a inadequação do modelo vigente e para a necessidade da mudança para um novo modelo de financiamento do crescimento.

\section{REGIME DE CRESCIMENTO COM POUPANÇA EXTERNA E INTERNA}

A tese do crescimento com poupança externa remonta a uma época específica da industrialização de uma economia em desenvolvimento onde a principal característica desta economia é a inexistência de uma indústria de bens de consumo duráveis, insumos 
intermediários e bens de capital. Contando apenas com uma indústria de bens de consumo não duráveis a economia cresce importando o que não produz, criando uma dependência do exterior. Para eliminar a dependência ao priorizar apenas o mercado interno adota-se um programa de substituição de importações com vistas a reduzir os déficits crônicos de balanço de pagamentos e ao mesmo tempo avançar no processo de industrialização via produção local de insumos, bens intermediários e bens de consumo duráveis. Enquanto a substituição de importações não atinge a última fase com a criação de uma indústria de bens de capital local, os déficits em transações permanecem, mudando-se apenas a pauta de importação. Mas ao mesmo tempo em que estão engajadas em programas de crescimento econômico estas economias sofrem dois efeitos limitantes. O primeiro é que estas economias apresentam uma alta elasticidade renda das importações, pelo que se justificam os programas de substituição de importações, e o segundo é que elas produzem e exportam produtos de baixo valor agregado ao mesmo tempo que importam produtos de alto valor agregado.

Quanto ao primeiro limitador do crescimento Thirlwall (1979) mostrou que no longo prazo a taxa de crescimento de uma economia tende a um nível que equilibra sua balança de pagamentos. Este nível é imposto pelo padrão tecnológico dos produtos exportados e importados e pela disponibilidade interna ou externa de bens de consumo e insumos intermediários. A taxa de crescimento que equilibra o balanço de pagamentos no longo prazo é dada então pela divisão entre a elasticidade renda das exportações e a elasticidade renda das importações. Se o crescimento for maior que o nível de equilíbrio as importações serão maiores que as exportações e haverá déficits em transações correntes com todos seus efeitos adversos sobre a economia, como tendência há valorização do câmbio, aumento da dívida externa e aumento da vulnerabilidade externa. Os ajustes no balanço de pagamento tornam o processo de crescimento um tanto instável e cíclico, de forma que períodos de crescimento com acumulação de déficits são seguidos por períodos de recessão com ajustamento do balanço.

O segundo efeito limitador, demonstrado por Prebish (1949, 1973), é o atraso tecnológico e a especialização das economias em desenvolvimento em alguns produtos primários como fonte de obtenção de receitas de exportação para financiar os déficits em transações correntes. Esta propriedade intrínseca da estrutura econômica leva a uma deterioração da relação de trocas mantendo a economia num atraso relativo em relação aos países desenvolvidos que estariam, dinamicamente, sempre na fronteira tecnológica. A dificuldade em alcançar a fronteira implica também o prolongamento do tempo da restrição 
de Thirlwall, isto é, posterga a redução da elasticidade renda das importações. A especialização em algumas commodities pode também conduzir a economia ao que tem sido chamado de doença holandesa. Uma situação em que as vantagens comparativas num determinado conjunto de commodities são tão grandes que mesmo com uma taxa de câmbio apreciada, a atividade exportadora se mantém viável. O câmbio apreciado não inviabiliza a exportação de commodities, mas inviabiliza a exportação de produtos de mais alto valor agregado ao mesmo tempo inibe o desenvolvimento da indústria local que se vê estimulada a importar ao invés de produzir internamente. Operando sobre a restrição de Thirlwall e com termos de troca desfavorável, as economias em desenvolvimento estão sujeitas a crônicos déficits em transações correntes.

A fim de superar tais gargalos, os países em desenvolvimento têm buscado pelo menos dois diferentes modelos de financiamento do crescimento: o primeiro modelo combina aumento de exportações inicialmente explorando vantagens comparativas ${ }^{22}$ e em seguida diversificando a pauta das exportações de manufaturados impulsionada por uma política cambial pró-exportadora com a subsequente geração de poupança interna; o segundo modelo recorre ao endividamento externo e atração de capital financeiro e investimento estrangeiro direto (IED) como meio de financiar as transações correntes deficitárias, ou em outras palavras através de poupança externa. Estas duas opções de financiamento do crescimento configuram duas estratégias de crescimento distintas usadas por países em desenvolvimento com diferentes resultados em termos de crescimento de longo prazo. A diferença reside basicamente na estratégia adotada para suportar os déficits em transações durante o período de transição até que o processo de industrialização alcance estágio maduro.

O Brasil tem utilizado o segundo modelo, optando por empréstimos e por atração de capital na forma de investimento direto e investimento em carteira, como forma de financiar os déficits de transações correntes. Adotou-o nos anos 1950 a 1970 como suporte ao programa de substituição de importações (TAVARES, 1972; CASTRO, 1985) e desde os 1990 até 2008 como suporte ao programa de combate à inflação ancorada em câmbio e estímulo ao crescimento via abertura comercial e choque de produtividade (BARROS; GIAMBIAGI, 2008). Colheu como resultado um processo de crescimento tortuoso, várias vezes interrompido pelas restrições macroeconômicas e externas que o modelo impõe. A crise da dívida externa nos anos 1980 e os ataques especulativos de 1999 e 2002 foram consequências do regime macroeconômico acoplado ao esquema de crescimento com

${ }^{22}$ Como no caso do café brasileiro no início da industrialização do país (FURTADO, 1970). 
poupança externa. Os países asiáticos, por sua vez, têm usado o primeiro modelo obtendo um crescimento de longo prazo mais robusto e sustentado que o brasileiro.

O modelo de crescimento com poupança externa em uso pelo Brasil até 2008, e a arquitetura macroeconômica que dá suporte a este modelo, explicam o crescimento do país abaixo da média mundial e da América Latina desde os anos 1980. Os principais fatores macroeconômicos por trás do pífio e oscilante crescimento observado são combinação de política monetária restritiva e regime de câmbio com taxa apreciada. Eficiente para reduzir preços, o modelo impõe um custo muito alto em termos de crescimento, expõe a economia ao desequilíbrio externo e inibe o florescimento e consolidação da indústria mais intensiva em tecnologia. A razão disso é que o financiamento com poupança externa resulta em determinados momentos com câmbio apreciado e isto gera diversos efeitos colaterais indesejados e que se autoalimentam.

Uma das justificativas do modelo de crescimento com poupança externa é que o país poderá aumentar a oferta interna e modernizar a indústria via importação de bens de capital, é necessário um câmbio valorizado para viabilizar os investimentos e garantir a capacidade de pagamento dos tomadores de empréstimo externo. O câmbio valorizado tem ainda um apelo populista, pois torna o salário real mais alto na medida em que os preços importados diminuem. Aqui surge a primeira contradição e efeito colateral do modelo. O aumento da oferta interna é restringido pelo desvio da demanda interna para o exterior anulando parcialmente a taxa de crescimento da economia. Outro efeito indesejado é que os déficits em transações correntes precisam ser financiados com entrada de capital financeiro via balança de capitais. Esta entrada pode ser feita por meio de IED e por meio de investimento em carteira. O primeiro canal só representa ampliação da oferta e, portanto, crescimento se for direcionado para novas instalações. Não foi o que ocorreu no Brasil entre 1994-2003, ocasião em que o IED entrou na forma de fusões e aquisições, provocando uma onda de concentração do capital em mãos estrangeiras. No médio prazo o capital estrangeiro irá remeter lucros para o exterior e é do seu interesse manter o câmbio o mais apreciado possível para que o lucro remetido represente mais poder de compra em moeda estrangeira. Este vetor volta-se contra o próprio equilibro externo desviando parte da poupança externa para alimentar as remessas de lucros. Este é o segundo efeito colateral indesejado. O terceiro efeito é que o regime de crescimento só é sustentado no médio e longo prazo se o país for capaz de atrair capital financeiro, de estrutura especulativa, como meio de equilibrar o balanço de pagamentos. Para atrair este tipo de capital o país se vê obrigado a elevar a taxa básica de 
juros num nível mais alto do que necessário, impondo uma política monetária contracionista, o que seria uma contradição com os objetivos principais de um modelo que visa o crescimento, mesmo com poupança externa. Há por fim um quarto efeito, como consequência da precariedade do equilíbrio externo nestas condições, o país é exposto a um maior grau de vulnerabilidade externa, podendo ser alvo de ataques especulativos contra a moeda e divisas, ou num cenário menos adverso, a uma maior volatilidade cambial, como tem acontecido nos últimos anos. Isto ocorreu duas vezes no Brasil recentemente, em 1999 e 2002. Nestas condições as tentativas de crescimento econômico são periodicamente abortadas pelas contradições macroeconômicas. A trajetória de longo prazo se torna incerta e a taxa média de crescimento ao longo dos ciclos de expansão e recessão é menor.

A origem da inadequação desta estratégia de crescimento baseada na poupança externa reside na forma com que o sistema de Bretton Woods, implantado em 1944, entrou em colapso no inicio dos anos 70 e a subsequente reorganização do sistema a partir deste momento. Dentro das regras de Bretton Woods o câmbio era fixo e sua paridade determinada internacionalmente. Neste ambiente a autonomia dos países estava limitada à estabilidade internacional. Foi esta combinação de uma maior autonomia dos países, mantida a estabilidade internacional, que permitiu o avanço de Bretton Woods em relação ao padrão ouro onde a estabilidade exigia a completa subordinação da autonomia dos países.

No novo cenário pós-crise de Bretton Woods, deflagrada em 1971, o câmbio passa a ser flutuante entre as principais moedas e a responsabilidade de sua fixação, em ultima análise, passar a ser dos estados nacionais. Neste regime o pêndulo novamente moveu-se em direção a maior autonomia dando mais espaço para os países perseguirem suas estratégias de crescimento. Mas por outro lado gerou menor estabilidade internacional. Segundo o FMI mais de 120 crises financeiras ou cambiais ocorreram desde o final de Breton Woods. Fases de expansão econômica nos países em desenvolvimento eram acompanhadas de utilização maciça de poupança externa, o que gerava déficits nas transações correntes que por sua vez acabavam em crises cambiais, desvalorizações fortes da moeda local e redução da atividade econômica, corte dos gastos públicos e crise social.

O modelo de crescimento puxado por exportação e com poupança interna não possui esta restrição e permite uma trajetória mais robusta e sustentada do crescimento. No entanto este modelo de crescimento, adotado largamente pelos asiáticos, possui o inconveniente, na forma de risco, de ancorar o seu crescimento no crescimento mundial. Um 
colapso da demanda externa dificulta as exportações, como está acontecendo na crise 20072008, colocando em cheque toda a estratégia de crescimento.

\section{CRESCIMENTO COM POUPANÇA INTERNA E REGIMES MONETÁRIOS}

Uma das principais características do modelo de crescimento baseado em exportação com poupança interna é a maior harmonia entre política monetária e cambial, muito embora possa aumentar a pressão sobre a inflação. No entanto o modelo propicia ou atenua o efeito sobre a inflação por conta da própria expansão da oferta que induz, de forma que a relação entre crescimento e inflação não é linear. Para que um país possa implementar um setor exportador pujante é necessário um mínimo de capacidade de administração da taxa de câmbio para manter uma taxa suficientemente competitiva que não inviabilize o florescimento e consolidação de uma indústria intensiva em tecnologia, mas não tão desvalorizada que gere pressões adicionais na inflação. Esta taxa de equilíbrio não deve necessariamente ser fixa, pois num cenário externo como o do pós-Bretton Woods e de globalização financeira o regime de câmbio fixo é muito difícil de administrar, senão impossível, como ficou bem evidenciado no ataque especulativo de 1999 no Brasil. Em termos de equilíbrio externo, uma taxa de câmbio industrialmente competitiva garante fluxos comerciais positivos e permite acumulação de reservas internacionais. Com reservas elevadas o país tem um maior poder sobre o câmbio real ao mesmo tempo em que reduz a volatilidade e vulnerabilidade externa. Toda a "blindagem" usada pelo Brasil na crise de 2007-2008 bem como parte do ciclo de crescimento 2004-2008 foi obtido ao mesmo tempo em que houve desvalorização cambial, acúmulo de reservas e redução de juros. Sem déficits em transações correntes o país libera sua política monetária, pois não se vê mais forçado a praticar uma taxa básica de juros elevada como meio de atrair capital ou conter a demanda. Esta liberação da política monetária atua em favor do crescimento econômico por três canais: a) exerce um efeito positivo direto dos juros sobre as decisões de consumo e investimento dos agentes privados; b) aumenta o espaço de política fiscal pró-crescimento, pois diminui a necessidade de financiamento do setor público ao reduzir o custo da rolagem de dívidas e c) evita ondas de valorização cambial por atrair menos capital de estrutura especulativa.

O modelo de crescimento baseado no crescimento da demanda externa ou exportações possui dois pontos críticos. O primeiro deles está fora do controle local e diz respeito ao cenário internacional. O modelo só funciona se houver demanda internacional suficiente para escoar o aumento da oferta. A queda da demanda internacional em razão da 
crise financeira de 2007-2008 produzirá efeitos amplificados nos países exportadores cujo grau de abertura comercial é muito alto. O segundo ponto crítico é a sua capacidade de geração interna de poupança. Um dos argumentos contra modelos de crescimento com poupança interna em países em desenvolvimento é a baixa capacidade de geração interna de poupança, por conta basicamente de dois fatores: a alta propensão marginal a consumir da população e a baixa capacidade de investir do Estado, que vê os recursos carreados para o atendimento e oferta de serviços públicos básicos. Isto é tanto mais forte quanto mais primitivo é o estágio de desenvolvimento industrial. No caso do Brasil, o argumento poderia ser aplicado nos anos 1930 a 1960, ocasião em que o país instituiu mecanismos de poupança forçada, como o FGTS e as instituições que dariam vazão à poupança para a atividade real como o antigo sistema Financeiro de Habitação (SFH) implementado em 1964 no Programa de Ação Econômica do Governo (PAEG). O argumento da insuficiência de poupança não se aplica mais no Brasil atual, pois o país apresenta um mercado de capitais e um setor bancário privado e público mais desenvolvido, bem como possui uma classe média muito mais populosa do que à época. É verdade que uma grande parcela da população é pobre, mas o fato é que o tamanho da economia formal é grande o suficiente para garantir a poupança de que necessita. Soa estranho e anacrônico que a economia brasileira, que possui o $10^{\circ} \mathrm{PNB}$ mundial seja considerada uma economia tão pequena que é incapaz de gerar poupança interna.

Além disto, devemos levar em conta que em economias monetárias desenvolvidas, como é a brasileira, as decisões de investimentos criam a poupança de que necessitam. A identidade entre poupança e investimento é uma tautologia que só faz sentido a posteriori enquanto medida contábil. Do ponto de vista dinâmico as decisões de investimentos são tomadas ex-ante, baseadas grande parte em expectativas (animal spirits) de modo que a procura de crédito é acomodada pelo setor bancário através de criação endógena de meios de pagamentos (MOORE, 1988). A poupança, portanto, não é uma variável restritiva, mas um reflexo contábil do investimento realizado.

Do exposto nesta seção e na anterior, fica evidente a inferioridade do modelo de mercado interno com poupança externa em relação ao modelo de crescimento puxado pelas exportações apoiado com poupança interna. A principal razão, como exposto, é a fragilidade e as contradições macroeconômicas que o primeiro modelo impõe. Mas estas duas opções não são as únicas. Modelos de crescimento puxados por exportações exigem como précondição um cenário internacional de crescimento da demanda mundial. É um modelo de 
crescimento que funciona bem quando o mundo inteiro cresce. Este não é o cenário internacional que vai vigorar nos próximos três anos ou mais. O modelo de crescimento asiático, que poderíamos chamá-lo de sino-americano, não seria de todo aplicado ao Brasil, por conta da restrição e dificuldades de aumentar exportações em plena recessão.

\section{UM MODELO DE CRESCIMENTO COM POUPANÇA INTERNA}

O Brasil deveria procurar um terceiro modelo alternativo. Este modelo deve levar em conta dois fatores estruturantes. O primeiro fator é um elemento de conjuntura que poderá mudar no futuro, mas não tão logo. Trata-se da retração da demanda mundial. Portanto, não poderá ancorar o impulso de crescimento à demanda externa como o fez no último ciclo de crescimento 2003-2008. A demanda necessária ao estímulo do investimento deverá vir de dentro da economia. O segundo fator é o sistema de financiamento do crescimento econômico. Dada a crise financeira mundial e seu prolongamento, a brutal retração de liquidez torna cada vez mais improvável a ocorrência de fluxos abundantes de capital produtivo e especulativo para os países em desenvolvimento. Depender destes fluxos para equilibrar o balanço de pagamentos iria exigir uma taxa de juros tão elevada que levantaria dúvidas sobre a capacidade financeira do governo de sustentá-la. As fontes de financiamento externo estarão reduzidas por um período prolongado. Mostramos na seção dois que as contradições internas do modelo de crescimento com poupança externa inviabilizam o modelo no longo prazo mesmo quando há liquidez internacional, o que se diria então num momento de crise financeira como o mundo está passando?

O primeiro pilar de um modelo com poupança interna é a política cambial. O Brasil deve implementar um modelo de crescimento que preserve os estímulos à liberalização comercial, isto é gerando condições para o crescimento das exportações e importações simultaneamente. Para isto a taxa de cambio real deve preservar o equilíbrio de transações correntes no longo prazo. No curto prazo a maxidesvalorização cambial ocorrida em 2008 combinada com o esvaziamento da bolha das commodities e a contração do crédito doméstico evitam que o ajuste de câmbio se converta em inflação. Trata-se, portanto, de uma estratégia de manutenção do câmbio real para simultaneamente preservar o equilíbrio externo e interno. A maior contribuição deste novo equilíbrio da taxa de câmbio real será a contenção das importações, mais do que o estímulo às exportações. A recessão internacional dos países industrializados e efeito sobre os países asiáticos que dependem das exportações tende a causar uma onda de mercantilismo e acirramento das estratégias defensivas de cada país. A 
manutenção da competitividade do cambio ajudará o Brasil a blindar seu balanço de pagamentos do desespero dos asiáticos e da Alemanha por manter suas exportações e proteger seu crescimento a qualquer custo. Á medida que a normalidade mundial for restaurada o cambio deixará a economia preparada para competir de mercado mundial e em condições de sair à frente de outros países e assim recuperar sua posição no cenário mundial como economia emergente de fato.

O segundo pilar deve ser a proteção e mobilização da demanda interna. A teoria macroeconômica tradicional tem privilegiado ora a taxa de juros ora a taxa de lucro como determinante do investimento. Além destes determinantes é necessário levar em conta de um lado a importância da inovação e de outro lado o efeito da demanda efetiva sobre a decisão de investimento. As condições necessárias para o crescimento dos investimentos é a existência de um conjunto de inovações a serem introduzidas na estrutura produtiva e de uma demanda crescente. Em economias de mercado com estrutura oligopolística alguns setores têm a capacidade de determinar sua taxa de mark-up e garantir a taxa de lucro mesmo num cenário recessivo. A taxa de lucro, portanto, não é a única variável macroeconômica relevante para a decisão de investimento. É importante como fonte interna de poupança para investimento, mas não seu determinante principal. Este papel cabe às inovações e à demanda efetiva, que garante a realização da expansão da produção.

Dados os dois pilares, câmbio e investimento, o restante do modelo de crescimento apropriado ao Brasil deve levar em conta o papel específico da política monetária e fiscal. Com uma taxa de juros real elevada e com superávit fiscal da ordem de 3\% a 4\% do PIB a política macroeconômica será sempre contracionista. A fim de estimular o crescimento o país deve contar com os dois instrumentos, monetário e fiscal. No curto prazo dada a situação específica que o país se encontra, a política monetária deve ser usada antes. O Brasil está numa situação diferente dos demais países porque possui um vasto espaço para redução da taxa de juros, redução dos compulsórios à vista e a prazo e redução de impostos sobre operações financeiras. Por ocasião da crise financeira e do longo processo de redução das taxas de juros os principais países desenvolvidos entraram na armadilha de liquidez já em 2008, com o que exauriram sua política monetária já nos primeiros dias de crise. Não poderão contar com ela na fase de recuperação da economia. A economia brasileira, neste aspecto, está numa situação diametralmente oposta. A taxa de juros real prevalecente no Brasil é um ponto fora da curva de normalidade. A política monetária é, para o Brasil, o melhor instrumento no momento. Uma redução mais agressiva dos juros diminuirá o custo de rolagem da dívida, 
diminuirá a pressão sobre o orçamento público abrindo mais espaço para políticas fiscais expansionistas compatíveis com a sustentabilidade e até mesmo queda da relação dívida/PIB além de exercer os tradicionais efeitos sobre os investimentos e consumo. Um luxo que outros países não têm. É preciso então explorar mais rapidamente o canal monetário antes de ter que entrar no perigoso terreno do endividamento público como forma de garantir que a demanda interna permanecerá suficientemente aquecida para manter o crescimento em patamar desejável.

$\mathrm{O}$ uso da política monetária preservará a política fiscal, que tem um custo maior. $\mathrm{O}$ Japão de 1990 é um caso emblemático, em pequena escala, do que poderá se converter o esforço de combate à crise com abuso de política fiscal. Usando a política fiscal como único instrumento que restou, após cair em armadilha da liquidez, o Japão acumulou uma dívida que estava no final de 2008 em 197\% do PIB (FMI). Os EUA estavam com 67\% do PIB antes de anunciar os planos de ajuda. Deverão fechar 2009 com 72\% a 75\%. Por muito menos outras economias quebraram e foram alvo de crise externa e especulação. A maioria dos países desenvolvidos enfrentará em breve uma forte restrição na capacidade do governo resgatar a economia. Esta restrição virá na forma da imposição de equilíbrio intertemporal do setor público. O violento esforço fiscal para interromper a queda da produção no mundo desenvolvido vai contaminar os orçamentos públicos e inflar as dívidas públicas. O resultado final do esvaziamento das bolhas financeiras será o enchimento de uma nova bolha de dívidas públicas. Se o Brasil usar mais agressivamente a política monetária agora, por não estar em armadilha de liquidez, vai passar ao longe do problema fiscal e despontará após 2010 como o país mais preparado macroeconomicamente para crescer.

Em linhas gerais, um modelo adequado para sustentar o crescimento da economia brasileira em uma era de crise mundial é a manutenção do câmbio competitivo com estímulos à manutenção da demanda efetiva interna. Parte da demanda interna é garantida pela reorientação das importações via câmbio e parte pelo relaxamento da política monetária. $\mathrm{O}$ estímulo à demanda efetiva poderá ser obtido com política monetária expansionista e preservação do instrumento de política fiscal. Em última instância, poderá usar a política fiscal, tanto na forma de maior investimento, quanto no alívio da carga tributária, especialmente via imposto de renda sobre a classe mais pobre. 


\section{REFERÊNCIAS}

Barros, Otávio de; Giambiagi, Fábio; (2008). Brasil Globalizado: O Brasil em um mundo surpreendente, Rio de Janeiro: Elsevier, 2008.

Castro, Antonio B. de; Souza, Francisco E. P. de; (1985). A Economia Brasileira em Marcha Forçada, 3ª ed., São Paulo: Paz e Terra, 2004.

Gala, Paulo (2008). Efeitos da apreciação cambial na poupança interna: analise teórica e evidências para o Brasil, Economia e Tecnologia, Centro de Pesquisas Econômicas (CEPEC), Programa de Pós-Graduação em Desenvolvimento Econômico, Universidade Federal do Paraná (UFPR), vol 14, p.5-12.

Prebisch, Raul; (1949). O Desenvolvimento Econômico da America Latina e Alguns de seus Principais Problemas, in Bielschowsky, Ricardo; Cinquenta Anos de Pensamento na Cepal, Rio de Janeiro: Editora Record, 2000.

Prebisch, Raul; (1973). Problemas Teóricos e Práticos do Crescimento Econômico, in Bielschowsky, Ricardo; Cinquenta Anos de Pensamento na Cepal, Rio de Janeiro: Editora Record 2000.

Moore, B. J.; (1998). Horizontalists and Verticalists: the Macroeconomics of Credit Money, Cambridge-UK, Cambridge University Press.

Tavares, Maria da Conceição; (1981). Da Substituição de Importações ao Capitalismo Financeiro, $9^{\mathrm{a}}$ ed., Rio de Janeiro: Zahar Editores.

Thirlwall, (1979). The Balance of Payments Constraint as an explanation of international growth rate differences, Banca Nazionale del Lavoro Quarterly Review, p. 45-55, mar. 1979. 